\title{
Difficult colonoscopy score identifies the difficult patients undergoing unsedated colonoscopy
}

\author{
Hui Jia ${ }^{1+}$, Limei Wang ${ }^{1,2+}$, Hui Luo ${ }^{1+}$, Shaowei Yao ${ }^{1}$, Xiangping Wang ${ }^{1}$, Linhui Zhang ${ }^{1}$, Rui Huang ${ }^{1}$, Zhiguo Liu',
} Xiaoyu Kang ${ }^{1}$, Yanglin Pan ${ }^{*}$ and Xuegang Guo ${ }^{*}$

\begin{abstract}
Background: Many factors have been found to affect the difficulty of colonoscope insertion, such as age, gender, body mass index (BMI), history of abdominal surgery and operator etc. However, a scoring system may be more useful to predict the difficulty during colonoscopy.

Methods: The individual and procedure-related data of 616 patients undergoing colonoscopy were prospectively collected from December 2013 through February 2014 in Xijing Hospital of Digestive Diseases. Cox regression analysis was used to identify high-risk factors associated with difficulty of colonoscopy. A predicting model with the difficult colonoscopy score (DCS) was developed.

Results: Total cecum intubation rate was 98.9\% (609/616). Advanced age, lower BMI, inexperienced operator and fair or poor sleep quality were identified as independent factors of prolonged insertion time (all $p<0.05$ ), which were used to develop the DCS. Based on the score, patients could be divided into high-risk and low-risk groups with distinct incomplete rates within 10 min $(42.0 \%$ vs. $16.5 \%, p<0.001)$. Compared with those with DCS $\leq 1$, patients with DCS $>1$ had increased insertion time $(10.6 \pm 0.7 \mathrm{~min}$ vs. $6.9 \pm 0.2 \mathrm{~min}, p<0.001)$ and pain score (1.9 \pm 1.5 vs. $1.4 \pm 1.4, p=0.002)$. More abdominal compression $(36.9 \%$ vs. $16.8 \%, p<0.001)$ and position change $(51.4 \%$ vs. $22.6 \%, p<0.001)$ were needed in this group of patients.

Conclusion: Patients with DCS $>1$ had longer insertion time, higher pain score and needed more abdominal compression and position changes. DCS was useful for predicting the difficulty of colonoscope intubation. (ClinicalTrials.gov NCT02105025 05/05/2014).
\end{abstract}

\section{Background}

Colonoscopy is widely used for management of colorectal diseases. Several indicators reflect the performance quality of colonoscopy, including adenoma detection rate, adverse events rate, withdrawal time and cecal intubation rate [1,2]. A high rate of cecal intubation is necessary for achieving a complete and thorough examination of the colon. According to the recommendations of the US Multi-society Task Force on Colorectal Cancer, cecal intubation rate above $90 \%$ in all examinations and above $95 \%$ in screening colonoscopy should be achieved by endoscopists [3].

\footnotetext{
* Correspondence: panyanglin@gmail.com; xuegangguo@gmail.com ${ }^{\dagger}$ Equal contributors

'Xijing Hospital of Digestive Diseases, Fourth Military Medical University, Xian, China

Full list of author information is available at the end of the article
}

Although completion rates have been reported as more than $95 \%$ in many studies $[4,5]$, colonoscopists do meet difficulties during colon insertion in some situations. It often needs tremendous efforts and prolonged insertion time in difficult patients. Although there is no standard definition of difficult colonoscopy, procedures with more than $10 \mathrm{~min}$ for insertion or at least two attempts to reach the cecum, or finally failed intubation are often considered difficult [6,7]. Because nearly all of the procedures of failed intubation or several attempts for insertion take at least $10 \mathrm{~min}$, prolonged insertion time ( $>10 \mathrm{~min})$ seems to be an appropriate and quantitative surrogate of insertion difficulty.

Several studies has revealed that some variables are risk factors of difficulty of colonoscopy, including gender, age, obesity, bowel preparation, and history of abdominal and/or pelvic surgery and complicated diverticular disease 
etc [7-13]. Difficulty of colonoscopy may be determined by a combination of these factors. Nakamura et al. proposed a scoring system base on these factors could be calculated prior to the procedure in order to prediction of difficult colonoscopy [14]. However, it was a pilot study and only 30 patients were enrolled.

Here we prospectively collected the data of insertion during colonoscopy and investigated the possible risk factors associated with prolonged insertion time by multivariate regression analysis. Furthermore, we developed a scoring system to predict the difficulty of colonoscopy.

\section{Methods}

\section{Patients}

This prospective study was conducted in the Endoscopy Center of Xijing Hospital of Digestive Diseases in China. Consecutive patients aged 18-90 years old who underwent unsedated colonoscopy were enrolled. Exclusion criteria included: (1) no bowel preparation or colon cleansing by enema only; (2) unnecessary to reach cecum; (3) prior finding of severe colon stenosis or obstructing tumor; (4) history of colectomy; (5) unstable hemodynamics; (6) pregenancy; (7) unable to give informed consent.

Written informed consent was obtained from all the patients. The study protocol and informed consent form were approved by the institutional review board of Xijing Hospital. This study was registered with Clinical Trials. gov (NCT02105025 05/05/2014).

\section{Bowel preparation and unsedated colonoscopy}

All patients were prescribed polyethylene glycol electrolyte powder (PEG-ELP, each sachet containing $59 \mathrm{~g}$ polyethylene glycol 4000, $1.46 \mathrm{~g}$ sodium chloride, $5.68 \mathrm{~g}$ sodium sulfate, $0.74 \mathrm{~g}$ potassium chloride, $1.68 \mathrm{~g}$ sodium bicarbonate; WanHe Pharmaceutical Co, Shenzhen, China) or sodium phosphate (Fleet Phospho-soda; CB Fleet Company, Switzerland) for bowel preparation according to the preference of physicians. They were asked to drink two bags of PEG-ELP dissolved in $2 \mathrm{~L}$ of water, or $45 \mathrm{~mL}$ of sodium phosphate be diluted in $240 \mathrm{~mL}$ of cool water following with at least $1.5 \mathrm{~L}$ of water at 05:00-06:00 h within $2 \mathrm{~h}$ on the day of colonoscopy. Patients were encouraged to drink more clear liquids after purgatives for adequate hydration before colonoscopy. In addition, patients were instructed to have a regular meal for lunch and only liquid diets for dinner the day before the operation. This preparation method had previously reported with acceptable cleansing rate, tolerance and polyp detection rate [15-18]. The quality of bowel preparation was evaluated by Ottawa scoreduring withdrawal of colonoscopy as described previously [19].

All colonoscopies were performed at 08:00-13:00 AM, 18 colonoscopists participated in this study and were categorized as senior if they had performed 1000 or more colonoscopies independently and junior if they had performed less than 1000 colonoscopies independently. The Fujinon colonoscope (CV-240, Japan) was used for every procedure. Air was insufflated during insertion and withdrawal.

\section{Data collection and outcomes measurement}

Demographic data and clinical characteristics of all patients were collected. The degree of maximum abdominal pain during the procedure was assessed by using visual analog scale (VAS) with 10-point scale $(1=$ no pain and $10=$ severe and intolerable pain). Anxiety was evaluated by Hospital Anxiety and Depression scale (HAD) as described previously [20]. Sleep quality was collected through questionnaires by interviewing patients before the procedure by a special staff, which was categorized as excellent or good, fair or bad as described previously [15,21]. During scope intubation, the maneuvers of abdominal compression and position changes were recorded. Cecal insertion time was recorded from the beginning of insertion to visualization of any of the following anatomical landmarks: ileocecal valve, appendiceal orifice or terminal ileum. If any doubt existed, the colonoscopy was defined as incomplete. All data were collected by one investigator (WLM) who did not participate in data analysis.

\section{Statistical analysis}

As an event-driven longitudinal procedure, KaplanMeier analysis provides a better means of assessment for determining the period than cross-sectional tests [22]. In the present study, only patients with the scope insertion to cecum were defined as "censored cases" (=success). Others were defined as termination due to "failure" (=failure). Log-rank test was used to assess the effect of single variable on insertion time. To adjust confounding factors, multivariate analysis (Cox regression analysis) was used for those covariates with $\mathrm{p}$ values of $<0.1$ in single factor analysis. A DCS was developed in line with the regression coefficients of the significant variables of multivariate regression analysis. The cutoff values of DCS were determined by receiver operator characteristics (ROC) analysis of cecal intubation completed within $10 \mathrm{~min}$. Continuous variables were expressed as means with standard deviation (SD) and analyzed with Student's t test or one-way ANOVA. Categorical variables were analyzed using chi-square test or Fisher exact test when appropriate. Analyses were performed with SPSS V.17.0 for Windows (IBM). All reported p-values were results of two-side test and those $<0.05$ was considered to be significant. 


\section{Results}

\section{Baseline of patient characteristics}

From December 2013 to February 2014, a total of 1253 patients undergoing unsedated colonoscopy were prospectively enrolled in our endoscopy center. 637 patients were excluded, among which 62 did not meet inclusion criteria (including 56 less than 18 years old and 6 above 90), 239 met exclusion criteria (including 137 with history of colectomy, 59 without bowel preparation and 43 with severe colon stenosis) and 336 denied to participate in this study. Finally 616 patients entered in this study. Total cecum intubation rate was $98.9 \%(609 / 616)$, with 7 patients failed because of poor bowel preparation $(n=4)$ and technical difficulty $(\mathrm{n}=3)$. The 4 failed patients with poor bowel preparation were excluded from final data analysis (Figure 1). The mean age of the study population was $50.4 \pm 14.0$ years, $315(51.5 \%)$ were males and $500(81.7 \%)$ received education of high school or above (Table 1). For the patients with successful intubation, the mean insertion time was $7.4 \pm 5.2 \mathrm{~min}$. $20.9 \%$ of patients had an insertion time of more than $10 \mathrm{~min}$. There was no complications were found in all patients.

\section{Factors associated with insertion time by univariate and multivariate analysis}

By univariate analysis (Table 2), the mean insertion time was found to be shorter in patients less than 65 years old than those more than $65(7.4 \pm 0.3 \mathrm{~min}$ vs. $9.0 \pm 0.6 \mathrm{~min}, \mathrm{p}=0.020)$. Men had a shorter insertion time than woman $(7.1 \pm 0.3 \mathrm{~min}$ vs. $8.2 \pm 0.4 \mathrm{~min}$, $\mathrm{p}=0.019)$. Colonoscopies $(\mathrm{n}=198)$ performed by junior endoscopists $(n=9)$ required longer insertion time than colonoscopies $(\mathrm{n}=414)$ performed by seniors

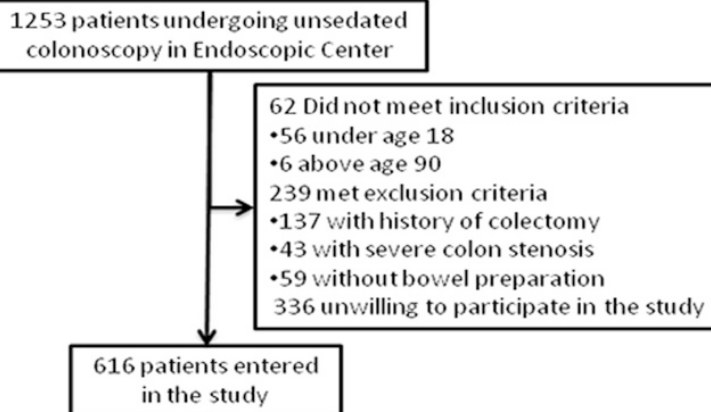

Figure 1 Flowchart of the study.
Table 1 Baseline of patient characteristics

\begin{tabular}{ll}
\hline Clinical features & Patients $(\mathbf{n}=\mathbf{6 1 2})$ \\
\hline Age (years) & $50.4 \pm 14.0$ \\
Gender & \\
Male & $315(51.5 \%)$ \\
Female & $297(48.5 \%)$ \\
BMI(kg/m2) & $22.7 \pm 3.7$
\end{tabular}

Grade of education

Elementary or below

$112(18.3 \%)$

High school or above

$500(81.7 \%)$

Marriage status

Single

34 (5.6\%)

Married

578 (94.4\%)

Smoking

$126(20.6 \%)$

Drinking

$136(22.2 \%)$

Patients type

Outpatient

486 (79.4\%)

Inpatient

$118(19.3 \%)$

Emergency

$8(1.3 \%)$

Previous surgery(abdominal and/or pelvic)

$162(26.5 \%)$

Diverticulosis

$10(1.6 \%)$

HAD

$2.6 \pm 4.4$

VAS

$1.5 \pm 1.4$

Symptoms

Constipation

$99(16.2 \%)$

Abdominal pain

$175(28.6 \%)$

Diarrhea

$98(16.0 \%)$

Others

$172(28.2 \%)$

Sleep quality

Excellent or good

$534(87.3 \%)$

Fair or bad

$78(12.7 \%)$

Indication for colonoscopy

Screening or surveillance

$137(22.4 \%)$

Diagnosis

475(77.6\%)

Interval time from appointment to

$8.5 \pm 6.9$

colonoscopy (days)

Purgative type

PEG-ELP

$550(89.9 \%)$

SP

62(10.1\%)

BMI, body mass index; HAD, Hospital Anxiety and Depression Scale; VAS, Visual Analogue Scale PEG-ELP, polyethylene glycol electrolyte powder; SP, sodium phosphate.

$(\mathrm{n}=9) \quad(\mathrm{p}=0,004)$. BMI were significantly associated with the insertion time to cecum $(p<0.001)$. According to the Kaplan-Meier curves (Additional file 1: Figure S1), the 3 higher BMI were combined for further multivariate regression analysis. Patients with fair 
Table 2 Univariate analysis of factors associated with insertion time duringunsedated colonoscopy

\begin{tabular}{|c|c|c|c|}
\hline Variable & $\mathbf{N}$ & Insertion time $(\mathrm{min})$ & $p$ value \\
\hline \multicolumn{4}{|l|}{ Age (years) } \\
\hline$<65$ & 518 & $7.4 \pm 0.3$ & \\
\hline$\geq 65$ & 94 & $9.0 \pm 0.6$ & 0.020 \\
\hline \multicolumn{4}{|l|}{ Gender (male/female) } \\
\hline Male & 315 & $7.1 \pm 0.3$ & \\
\hline Female & 297 & $8.2 \pm 0.4$ & 0.019 \\
\hline \multicolumn{4}{|l|}{ BMI (kg/m2) } \\
\hline Underweight (<18.5) & 68 & $10.8 \pm 1.0$ & \\
\hline Healthy weight (18.5-24.9) & 383 & $7.3 \pm 0.3$ & \\
\hline Overweight (25.0-29.9) & 145 & $7.2 \pm 0.5$ & \\
\hline Obesity $(\geq 30)$ & 16 & $6.4 \pm 0.9$ & $<0.001$ \\
\hline \multicolumn{4}{|l|}{ Colonoscopists } \\
\hline Senior $(n=9)$ & 414 & $7.2 \pm 0.3$ & \\
\hline Junior $(n=9)$ & 198 & $8.5 \pm 0.4$ & 0.004 \\
\hline \multicolumn{4}{|l|}{ Sleep quality } \\
\hline Excellent or good & 534 & $7.3 \pm 0.2$ & \\
\hline Fair or bad & 78 & $9.7 \pm 1.0$ & 0.004 \\
\hline \multicolumn{4}{|l|}{$\begin{array}{l}\text { Interval time of appointment to } \\
\text { colonoscopy (days) }\end{array}$} \\
\hline$<10$ & 348 & $8.0 \pm 0.3$ & \\
\hline$\geq 10$ & 264 & $7.1 \pm 0.3$ & 0.065 \\
\hline \multicolumn{4}{|l|}{ Smoking } \\
\hline Yes & 126 & $7.0 \pm 0.5$ & \\
\hline No & 486 & $7.7 \pm 0.3$ & 0.089 \\
\hline
\end{tabular}

BMI, body mass index.

or bad sleep quality had a longer insertion time than the others $(p=0.004)$. Smokers tended to have shorter insertion time than nonsmokers although the difference was not significant $(\mathrm{p}=0.089)$. If the interval time of appointment-to-colonoscopy was less than 10 days, the insertion time tended to be shorter $(\mathrm{p}=0.065)$. There were no differences of insertion time regarding patients with different education levels, marital status, symptoms, history of surgery, anxiety (by HAD score), patient types and indications of colonoscopy etc.

Table 3 provided an outline of multivariate analysis. Of all the factors associated with insertion time $(\mathrm{p}<0.1)$ found by univariate analysis, only four factors had independent impact on insertion time during colonoscopy. Colonoscopy performed by junior colonoscopists (HR 1.29; 95\% CI, 1.081.54; $p=0.004)$, patients with fair or bad sleep quality (HR 1.33; 95\% CI, 1.04-1.72; $\mathrm{p}=0.026$ ), those with $\mathrm{BMI}<18.5$ (HR 1.59; 95\% CI, 1.23-2.07; $\mathrm{p}=0.001$ ) or age $\geq 65$ (HR 1.29 ; $95 \% \mathrm{CI}, 1.03-1.62 ; \mathrm{p}=0.027$ ) were independently associated with longer insertion time.
Table 3 Multivariate analysis of factors associated with insertion time during unsedated colonoscopy

\begin{tabular}{|c|c|c|c|c|c|}
\hline Variables & $N=612$ & HR $(95 \% \mathrm{Cl})$ & $p$ value & B score & $\begin{array}{l}\text { DCS } \\
\text { points }\end{array}$ \\
\hline \multicolumn{6}{|l|}{ Age (years) } \\
\hline$<65$ & 518 & & & & \\
\hline$\geq 65$ & 94 & $1.29(1.03-1.62)$ & 0.027 & 0.26 & 1 \\
\hline \multicolumn{6}{|l|}{ BMI (kg/m2) } \\
\hline$\geq 18.5$ & 544 & & & & \\
\hline$<18.5$ & 68 & $1.59(1.23-2.07)$ & 0.001 & 0.47 & 2 \\
\hline \multicolumn{6}{|l|}{ Colonoscopists } \\
\hline Senior & 414 & & & & \\
\hline Junior & 198 & $1.29(1.08-1.54)$ & 0.004 & 0.26 & 1 \\
\hline \multicolumn{6}{|l|}{ Sleep quality } \\
\hline $\begin{array}{l}\text { Excellent } \\
\text { or good }\end{array}$ & 534 & & & & \\
\hline Fair or bad & 78 & $1.33(1.04-1.72)$ & 0.026 & 0.29 & 1 \\
\hline
\end{tabular}

\section{Deviation of a predicting model to predict difficult colonoscopy}

To facilitate establishing a prediction model of insertion time of colonoscopy, the regression coefficients (B-score) of four independent factors were multiplied by 4 and rounded. Thus, DCS $=1 \times \mathrm{A}$ ( 1 if age $\geq 65 \mathrm{y}$, 0 if $<65 \mathrm{y})+2 \times \mathrm{B}(1$ if $\mathrm{BMI}<18.5,0$ if $\geq 18.5)+1 \times \mathrm{C}$ ( 1 if colonoscopist is junior, 0 if senior $)+1 \times \mathrm{S}$ ( 1 if sleep quality was fair or bad, 0 if excellent or good) (Table 3 ). Then, we got a 6 point scoring system ( $0-5$ point), and we found as the score rose the insertion time prolonged and the difficult rate increased. From $0-5$ point, the insertion time was $6.4 \pm 5.1,7.5 \pm 5.0,9.9 \pm 7.0,11.7 \pm 9.2$, $14.0 \pm 5.3,15.0 \pm 11.0$ respectively, $\mathrm{p}=0.006$. The rate of insertion time of more than 10 minwas $12.4 \%, 21.1 \%$, $35.4 \%, 47.4 \%, 60.0 \%, 66.7 \%$ respectively, $\mathrm{p}<0.001$ (Table 4.). Next, we performed a ROC curve, the area under the ROC for predicting difficult colonoscopy (insertion time more than $10 \mathrm{~min}$ ) was 0.66 , with an optimal threshold of 1 point (Additional file 2: Figure S2). The sensitivity, specificity, positive and negative predictive value of DCS $>1$ for the prediction of difficult colonoscopy was $73 \%, 50 \%, 85 \%$ and $66 \%$ respectively. Base on ROC curve, patients could be divided into low$\operatorname{risk}(\mathrm{DCS} \leq 1)$ and high-risk $(\mathrm{DCS}>1)$. Compared with low-risk patients, the difficult rate in high-risk patients with DCS $>1$ was higher $(16.5 \%$ vs. $42.0 \%, \mathrm{p}<0.001)$.

\section{Effect of different DCS on the difficulty-related variables of colonoscopy}

We further analyzed the difference of insertion time, maximal pain sore and the need of abdominal compression and position changes in patients with different DCS 
Table 4 The effects of different DCS on the colonoscopy

\begin{tabular}{llllllll}
\hline & DCS value & & & \\
\cline { 2 - 8 } & $\mathbf{0}$ & $\mathbf{1}$ & $\mathbf{2}$ & $\mathbf{3}$ & $\mathbf{4}$ & $\mathbf{5}$ & P value \\
\hline Insertion time (min) & $6.4 \pm 5.1$ & $7.5 \pm 5.0$ & $9.9 \pm 7.0$ & $11.7 \pm 9.2$ & $14.0 \pm 5.3$ & $15.0 \pm 11.0$ & 0.006 \\
Difficult rate & $12.4 \%$ & $21.1 \%$ & $35.4 \%$ & $47.4 \%$ & $60.0 \%$ & $66.7 \%$ & $<0.001$ \\
\hline
\end{tabular}

DCS, difficult colonoscopy score.

(Table 5). Patients with DCS $>1$ had a significantly longer insertion time compared with those with DCS $\leq 1$ $(10.6 \pm 0.7 \mathrm{~min}$ vs. $6.9 \pm 0.2 \mathrm{~min}, \mathrm{p}<0.001)$. The maximal pain score in patients with DCS $>1$ was $1.9 \pm 1.5$ which was higher than $1.4 \pm 1.4$ in those with $\mathrm{DCS} \leq 1$ $(\mathrm{p}=0.002)$. More abdominal compression (36.9\% vs. $16.8 \%, \mathrm{p}<0.001)$ and position changes $(51.4 \%$ vs. $22.6 \%, \mathrm{p}<0.001$ ) were found in patients with DCS $>1$.

\section{DCS for prediction of difficulty in subgroups of patients} The effects of different DCS ( $\leq 1$ vs. $>1$ ) on difficulty of colonoscopy in subgroups of patients were further evaluated. The stratified factors included gender, presence of constipation, prior history of abdominal or pelvic surgery, anxious status (by HAD score), patient types, indications of colonoscopy and quality of bowel preparation. As shown in Figure 2, colonoscopy tended to be more difficult with longer insertion time in patients with DCS $>1$. This result was consistent nearly for all subgroups of patients (except for inpatients).

\section{Discussion}

It has been estimated that complete intubation of the colon is considerably difficult in up to $10-20 \%$ of procedures [23]. The difficulty of insertion during colonoscopy is largely related to looping of the colonoscope which displaces the colon from its native configuration. It is important to identify the potentially difficult cases before colonoscopy. Special intubation techniques or strategies, such as water-aided or cap-assisted method [24,25], single or double balloon

Table 5 The effects of different DCS groups on the procedure of colonoscopy

\begin{tabular}{llll}
\hline & DCS $>\mathbf{1}(\mathbf{n}=\mathbf{1 1 1})$ & $\mathbf{D C S} \leq \mathbf{1}(\mathbf{n}=\mathbf{5 0 1})$ & $\mathbf{p}$ value \\
\hline $\begin{array}{l}\text { Mean insertion } \\
\text { time (min) }\end{array}$ & $10.6 \pm 0.7$ & $6.9 \pm 0.2$ & $<0.001$ \\
Maximal pain score & $1.9 \pm 1.5$ & $1.4 \pm 1.4$ & 0.002 \\
Abdominal & $41(36.9 \%)$ & $84(16.8 \%)$ & $<0.001$ \\
compression (\%) & & & \\
Position change (\%) & $57(51.4 \%)$ & $113(22.6 \%)$ & $<0.001$ \\
\hline
\end{tabular}

DCS, difficult colonoscopy score. enteroscopy [26-29] or magnet-imaging enhanced colonoscopy [8] etc. can be used early in these groups of patient to avoid of excessive insertion time, increased discomfort and even unnecessary adverse events. In the present study, by using insertion time as a surrogate and quantitative endpoint of difficulty, four independent variables, including age, BMI, case volume of colonoscopists and sleep quality were identified as high-risk factors associated with intubation difficulty. Based on these factors, we developed a DCS to predict the prolonged insertion time and difficulty of colonoscopy. High-risk patients with DCS $>1$ had an increased mean insertion time (1.5 times) and pain score ( 1.4 times) and needed more abdominal compression (2.2 times) and position changes (2.3 times). For the patients with DCS $>1$, several strategies can be chosen, including appointment with senior endoscopist or intubating with pediatric scope [30]. Some techniques may also be used to facilitate scope insertion, such as water-aided or cap-fitted or magnetimaging enhanced method.

Several studies had revealed that some factors were related to the difficulty of colonoscope intubation, including advanced age, lower BMI, technical skill of the endoscopist, female gender, presence of constipation, history of abdominal or pelvic surgery, and inadequate bowel preparation $[10,11,31,32]$. However, the results among these studies were inconsistent. In the present study, we confirmed that the former three factors were associated with the insertion difficulty whereas the others were not. The different findings of risk factors among the studies may be mainly due to different study design, enrolled population, definitions of difficulty and the indications of colonoscopy. Regardless of the possibly other risk factors, the effectiveness of DCS was found to be consistent across nearly all subgroups of patients (Figure 2).

The present study revealed that sleep quality was an independent predictor of prolonged insertion time, which had not been examined in previous studies. Patients with fair or bad sleep quality was shown to have a longer insertion time. However, the reasons why sleep quality can affect the difficulty of colonoscopy are not clear. Some evidences suggested that the feeling of pain was related to sleep quality, with poor quality of sleep 


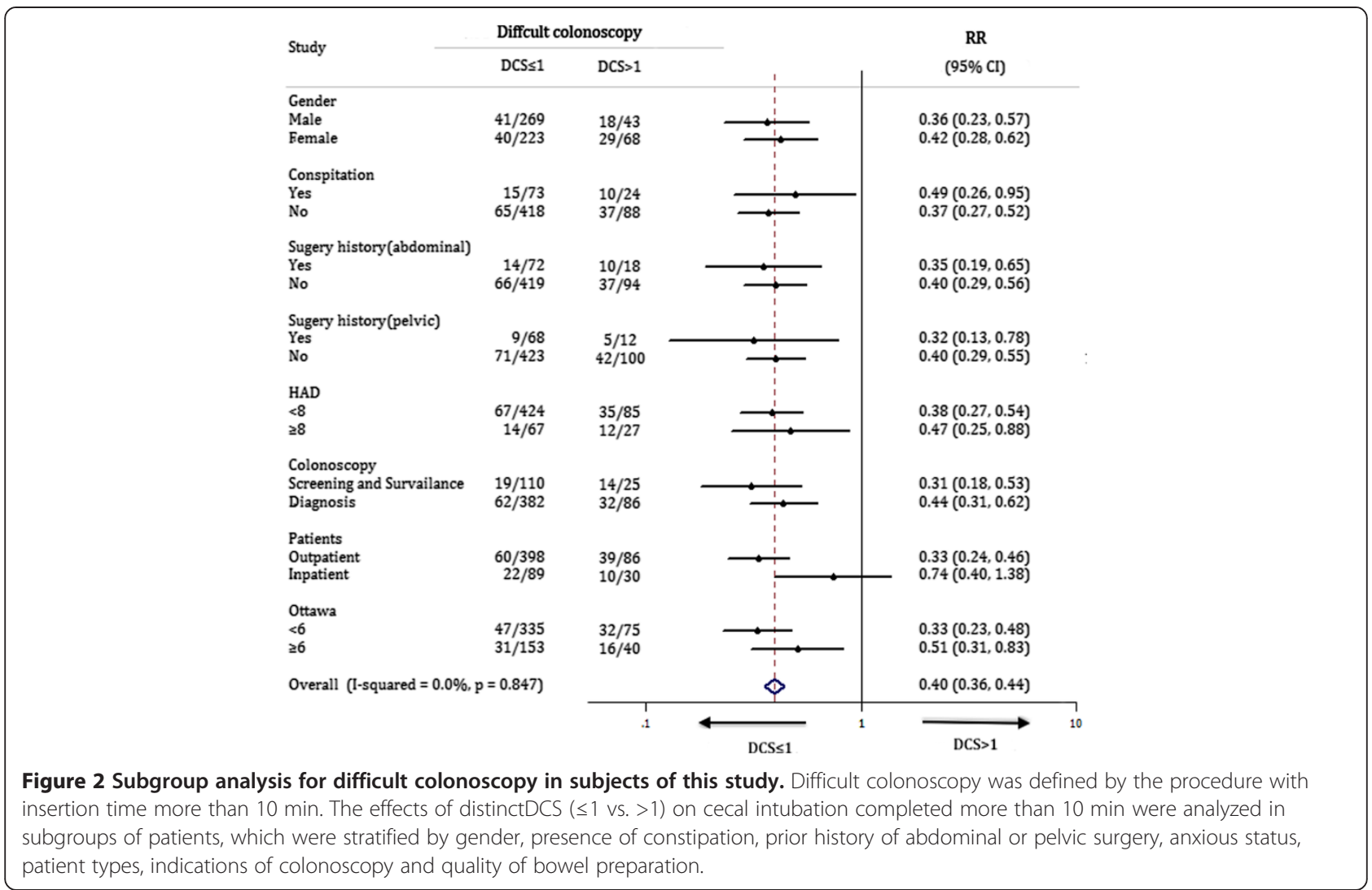

often independently associated with greater pain sensitivity [33]. In this study, the maximal pain score rated by patients with fair or bad sleep quality tended to be higher than those with excellent or good $(1.7 \pm 1.4$ vs. $1.5 \pm 1.4, \mathrm{p}=0.33$ ), although the difference was not significant. The difficulty of colonoscope intubation may be increased due to the poor tolerance of pain or discomfort in patients with poor sleep quality, especially in the situation of unsedated colonoscopy. Furthermore, it had been found that patients with fair or bad sleep quality tended to have inadequate bowel preparation in our previous study [15], which might also increase the difficulty of scope insertion.

There are some limitations of the present study. Firstly, the majority $(77.6 \%)$ of patients underwent diagnostic colonoscopy, which may limit its extrapolations. However, subgroup analysis showed that DCS was also effective in patients undergoing screening or surveillance colonoscopy. Secondly, this study was performed in patients with unsedated status. So there may be some confounding factors, such as levels of anxiety, the tolerance of pain or discomfort, directly associated with insertion time. Thirdly, our study only enrolled one group of patients as the training cohort for establishing the model. The external validation in another independent validation cohort was absent. Fourthly, air was insufflated instead of $\mathrm{CO} 2$ during colonoscopy. It will be interesting to investigate whether $\mathrm{CO}_{2}$ has potential impact on DCS in another study. Finally, the generalizability of this study may be limited by the clinical setting in which the examination were performed in only one tertiary center. Therefore, to avoid these influences, the conclusion needs further validation.

\section{Conclusions}

In summary, advanced age, lower BMI, inexperienced operator and relatively poor sleep condition were associated with longer insertion time, and we developed a novel, objective, noninvasive and conveniently applicable predictive score (DCS) to prejudge the potentially difficulty colonoscopy in preoperational stage.

\section{Additional files}

Additional file 1: Figure S1. Kaplan-Meier curves of insertion time in patients with different BMI.

Additional file 2: Figure S2. ROC analysis for the prediction of patients with insertion time less than 10 min by DCS. 


\section{Competing interests}

The authors declare that they have no competing interests. The authors alone are responsible for the content and writing of the paper.

\section{Authors' contributions}

$\mathrm{HJ}$ participated in the design of the study and performed the statistical analysis and draft the manuscript. LMW participated in the data collection and the design of the study. HL participated in the data interpretation and helped to draft the manuscript. YLP conceived of the study, and participated in its design and coordination and helped to draft the manuscript. LZG participated in the coordination. XGG participated in the coordination and give critical revision of the manuscript for important intellectual content. SWY, XYK participated in data interpretation. XPW, LHZ, and RH carried out the examination. All authors read and approved the final manuscript.

\section{Acknowledgment}

We thank the help of the nurses working in Endoscopic Center of Xijing Hospital of Digestive Diseases.

\section{Author details}

${ }^{1}$ Xijing Hospital of Digestive Diseases, Fourth Military Medical University, Xian, China. ${ }^{2}$ Shannxi Second People's Hospital, Xian, China.

Received: 15 October 2014 Accepted: 23 March 2015

\section{Published online: 09 April 2015}

\section{References}

1. Rex DK, Bond JH, Winawer S, Levin TR, Burt RW, Johnson DA. Quality in the technical performance of colonoscopy and the continuous quality improvement process for colonoscopy: recommendations of the U.S. Multi-Society Task Force on Colorectal Cancer. Am J Gastroenterol. 2002;97:1296-308.

2. van Doorn SC, van Vliet J, Fockens P, Dekker E. A novel colonoscopy reporting system enabling quality assurance. Endoscopy. 2014;46:181-7.

3. Rex DK, Schoenfeld PS, Cohen J, Pike IM, Adler DG, Fennerty MB. Quality indicators for colonoscopy. Am J Gastroenterol. 2015;110(1):72-90.

4. Rex DK, Goodwine BW. Method of colonoscopy in 42 consecutive patients presenting after prior incomplete colonoscopy. Am J Gastroenterol. 2002;97:1148-51.

5. Imperiale TF, Wagner DR, Lin CY, Larkin GN, Rogge JD, Ransohoff DF. Risk of advanced proximal neoplasms in asymptomatic adults according to the distal colorectal findings. N Engl J Med. 2000;343:169-74

6. Chung YW, Han DS, Yoo KS, Park CK. Patient factors predictive of pain and difficulty during sedation-free colonoscopy: a prospective study in Korea. Dig Liver Dis. 2007;39:872-6.

7. Chutkan R. Colonoscopy issues related to women. Gastrointest Endosc Clin N Am. 2006;16:153-63.

8. Arcovedo R, Larsen C, Reyes HS. Patient factors associated with a faster insertion of the colonoscope. Surg Endosc. 2007;21:885-8.

9. Anderson JC, Messina CR, Cohn W, Gottfried E, Ingber S, Bernstein G. Factors predictive of difficult colonoscopy. Gastrointest Endosc. 2001;54:558-62.

10. Kim WH, Cho YJ, Park JY, Min PK, Kang JK, Park IS. Factors affecting insertion time and patient discomfort during colonoscopy. Gastrointest Endosc. 2000;52:600-5

11. Bernstein C, Thorn M, Monsees K, Spell R, O'Connor JB. A prospective study of factors that determine cecal intubation time at colonoscopy. Gastrointest Endosc. 2005:61:72-5.

12. Aslinia F, Uradomo L, Steele A, Greenwald BD, Raufman JP. Quality assessment of colonoscopiccecal intubation: an analysis of 6 years of continuous practice at a university hospital. Am J Gastroenterol. 2006:101:721-31.

13. Hsu CM, Lin WP, Su MY, Chiu CT, Ho YP, Chen PC. Factors that influence cecal intubation rate during colonoscopy in deeply sedated patients. J Gastroenterol Hepatol. 2012;27:76-80.

14. Nakamura M, Murino A, Despott E, Suzuki N, Bourikas L, Man R, et al. Predicting.difficult colonoscopy using the St Mark's difficult colonoscopy system: a pilot study. Gut. 2012;61:A278-9.

15. Liu X, Luo H, Zhang L, Leung FW, Liu Z, Wang X. Telephone-based re-education on the day before colonoscopy improves the quality of bowel preparation and the polyp detection rate: a prospective, colonoscopist-blinded, randomised, controlled study. Gut. 2014;63:125-30.
16. Chiu HM, Lin JT, Wang HP, Lee YC, Wu MS. The impact of colon preparation timing on colonoscopic detection of colorectal neoplasms-a prospective endoscopist-blinded randomized trial. Am J Gastroenterol. 2006;101:2719-25.

17. Parra-Blanco A, Nicolas-Perez D, Gimeno-Garcia A, Grosso B, Jimenez A, Ortega J. The timing of bowel preparation before colonoscopy determines the quality of cleansing, and is a significant factor contributing to the detection of flat lesions: a randomized study. World J Gastroenterol. 2006;12:6161-6.

18. Church JM. Effectiveness of polyethylene glycol antegrade gut lavage bowel preparation for colonoscopy-timing is the key! Dis Colon Rectum. 1998:41:1223-5.

19. Rostom A, Jolicoeur E. Validation of a new scale for the assessment of bowel preparation quality. Gastrointest Endosc. 2004;59:482-6.

20. Soares-Filho GL, Freire RC, Biancha K, Pacheco T, Volschan A, Valenca AM. Use of the hospital anxiety and depression scale (HADS) in a cardiac emergency room: chest pain unit. Clinics (Sao Paulo). 2009;64:209-14.

21. Park SS, Sinn DH, Kim YH, Lim YJ, Sun Y, Lee JH. Efficacy and tolerability of split-dose magnesium citrate: low-volume (2 liters) polyethylene glycol vs. single- or split-dose polyethylene glycol bowel preparation for morning colonoscopy. Am J Gastroenterol. 2010;105:1319-26.

22. Balkenhol M, Wostmann B, Rein C, Ferger P. Survival time of cast post and cores: a 10-year retrospective study. J Dent. 2007;35:50-8.

23. Eickhoff A, Pickhardt PJ, Hartmann D, Riemann JF. Colon anatomy based on CT colonography and fluoroscopy: impact on looping, straightening and ancillary manoeuvres in colonoscopy. Dig Liver Dis. 2010;42:291-6.

24. Luo H, Zhang L, Liu X, Leung FW, Liu Z, Wang X. Water exchange enhanced cecal intubation in potentially difficult colonoscopy. Unsedated patients with prior abdominal or pelvic surgery: a prospective, randomized, controlled trial. Gastrointest Endosc. 2013;77:767-73.

25. Lee YT, Hui AJ, Wong WW, Hung LC, Sung JJ. Improved colonoscopy success rate with a distally attached mucosectomy cap. Endoscopy. 2006:38:739-42.

26. Keswani RN. Single-balloon colonoscopy versus repeat standard colonoscopy for previous incomplete colonoscopy: a randomized, controlled trial. Gastrointest Endosc. 2011;73:507-12.

27. Pasha SF, Harrison ME, Das A, Corrado CM, Arnell KN, Leighton JA. Utility of double-balloon colonoscopy for completion of colon examination after incomplete colonoscopy with conventional colonoscope. Gastrointest Endosc. 2007:65:848-53.

28. May A, Nachbar L, Ell C. Push-and-pull enteroscopy using a single-balloon technique for difficult colonoscopy. Endoscopy. 2006:38:395-8.

29. Hotta K, Katsuki S, Ohata K, Abe T, Endo M, Shimatani M. A multicenter, prospective trial of total colonoscopy using a short double-balloon endoscope in patients with previous incomplete colonoscopy. Gastrointest Endosc. 2012;75:813-8

30. Rex DK, Chen SC, Overhiser AJ. Colonoscopy technique in consecutive patients referred for prior incomplete colonoscopy. Clin Gastroenterol Hepatol. 2007;5(7):879-83.

31. Takahashi $Y$, Tanaka H, Kinjo M, Sakumoto K. Prospective evaluation of factors predicting difficulty and pain during sedation-free colonoscopy. Dis Colon Rectum. 2005;48:1295-300.

32. Zuber-Jerger I, Kullmann F. A prospective study of factors that determine cecal intubation time at colonoscopy. Gastrointest Endosc. 2006;63:358-9.

33. Goodin BR, Smith MT, Quinn NB, King CD, McGuire L. Poor sleep quality and exaggerated salivary cortisol reactivity to the cold pressor task predict greater acute pain severity in a non-clinical sample. Biol Psychol. 2012;91:36-41. 